\title{
Statistical analyses of fluorometry data from chloroform fil- trate of lamb feces
}

\author{
A. MUKHERJEE ${ }^{1}$, D.M. ANDERSON ${ }^{2}$, D.L. DANIEL ${ }^{3}$, L.W. MURRAY ${ }^{3}$, G. TISONE ${ }^{4}$, E.L. FREDRICKSON ${ }^{2}$, R.E. \\ ESTELL $^{2}$, G.D. RAYSON ${ }^{5}$, AND K.M. HAVSTAD ${ }^{2}$
}

\begin{abstract}
${ }^{I}$ Former graduate student, New Mexico State University, University Statistics Center, Las Cruces, N.M 88003-0003 (U.S.A.), ${ }^{2}$ research scientist, USDA, Agricultural Research Service, Jornada Experimental Range, Box 30003, NMSU, Dept. 3JER, Las Cruces, N.M. 88003-00033', statistician, New Mexico State University, University Statistics Center, Las Cruces, N.M. 88003-0003, ${ }^{4}$ president/physicist, TW Research Associates, 10212 Chapala Pl. NE, Albuquerque, N.M. 87111, ${ }^{5}$ associate professor, New Mexico State University, Department of Chemistry and Biochemistry, Las Cruces, N.M. $88003-0003$.
\end{abstract}

\begin{abstract}
Accurately identifying the botanical composition of free-ranging animal diets remains a challenge. Currently accepted procedures are time consuming, many requiring painstaking sample preparation while none produce data useful for real-time management. Automated procedures focusing on detection of chemical and/or physical plant properties using specific molecules called fluorophores offers possibilities for determining the species composition of herbivore diets. This study was designed to evaluate fluorometry techniques in herbivore diet determinations using fecal samples obtained from 13 lambs fed a basal diet of tobosa hay (Pleuraphis mutica Buckley), and containing 4 different levels $(0,10,20$, and $30 \%)$ of tarbush (Flourensia cernua $D$ C.) leaf material. Chloroform $\left(\mathrm{CHCl}_{3}\right)$ filtrate obtained from the lamb's feces was exposed to UV light from a xenon arc lamp. This caused fluorophore molecules in the filtrate to have their outer shell electrons move to a higher energy state as a result of UV light excitation. After excitation by UV light at 310, 320, 330, 340,350 , and $355 \mathrm{~nm}$, the fluorophores returned to their ground state giving off light (fluorescence). This fluorescence intensity (counts) varied and when captured using appropriate electronics, produced 1,024 pairs of light intensities (counts) and fluorescent wavelengths between 175 and $818 \mathrm{~nm}$ in $0.63 \mathrm{~nm}$ increments. Previous research indicated differences among diets could be determined using distinct peaks in the red and blue regions of the visible light spectrum and a univariate (1 variable at a time) analysis. This research demonstrates the entire fluorescence data set can be used to determine differences among diets using multivariate statistics. Sequences of 5 increasingly complex statistical techniques were used to distinguish among diets: 2-dimensional plots, polynomial regression models, confidence interval plots, discriminant analysis, and 3-dimensional plots. Two-dimensional plots indicated 2 spectral fluorescence peaks, 1 in the blue-green $(420-600 \mathrm{~nm})$ and 1 in the red $(640-720 \mathrm{~nm})$ region of the visible
\end{abstract}

Trade names used in this publication are solely for the purpose of providing specific information. Mention of a trade name does not constitute a guarantee, endorsement, or warranty of the product by the U.S. Department of Agriculture, New Mexico State University or Sandia National Laboratories over other products not mentioned.

The authors express sincere appreciation to Dr. Perry Gray, research scientist with the Pulsed Power and Laser Initatives Department Sandia National Laboratory, Albuquerque, N.M. for generating the spectral signatures from the sheep feces.

Manuscript accepted 7 Oct. 2000.

\section{Resumen}

El identificar en forma certera la composición botánica de la dieta de animales en libre pastoreo sigue siendo un reto. Los procedimientos actualmente aceptados consumen mucho tiempo y muchos requieren una laboriosa preparación de la muestra, mientras que ninguno produce datos útiles en términos de manejo real de tiempo. Los procedimientos automatizados enfocados a la detección de propiedades físico-químicas de las plantas mediante el uso de moléculas especificas llamadas fluroforos ofrecen posibilidades alentadoras para determinar la composición de especies de la dieta de los herbívoro. Este estudio se diseño para evaluar las técnicas de flurometría en la determinación de la dieta de herbívoros utilizando muestras fecales obtenidas de 13 corderos alimentados con una dieta basal de heno de toboso (Pleuraphis mutica Buckley) y conteniendo cuatro diferentes niveles $(0,10,20$, y $30 \%)$ de hojas "Tarbush" (Flourensia cernua D C.). Un filtrado de cloroformo $\left(\mathrm{CHCL}_{3}\right)$ obtenido de las heces de los corderos se expuso a la luz ultravioleta (UV)de una lampara de arco de xenón. Esto causo que los electrones de las órbitas exteriores de las las moléculas de los fluoroforos del filtrado cambiaran a un estado de alta energía resultante de la excitación por la luz UV. Después de la excitación por la luz UV a $310,320,330,340$ y $350 \mathrm{~nm}$, los fluoroforos regresaron a su estado inicial quedando sin fluorescencia. Esta intensidad de fluorescencia (conteos) variaron, cuando son capturados con los aparatos apropiados, produjeron 1,024 pares de intensidades de luz (conteos) y longitudes de onda fluorescente entre 175 y 818 $\mathrm{nm}$ con incrementos de $0.63 \mathrm{~nm}$. La investigación previa indica que la diferencia entre dietas pude ser determinada utilizando distintos picos en las regiones azul y roja del espectro de luz visible y un análisis univariado (1 variable a la vez). Esta investigación demuestra que el conjunto completo de los datos de fluorescencia puede ser utilizado para determinar diferencias entre las dietas mediante el uso de estadística multivariada. Se utilizaron las secuencias de 5 técnicas estadísticas que incrementan en complejidad para distinguir entre las dietas: gráficas bidimensionales, modelos de regresión polinomial, gráficas de intervalos de confianza, análisis discriminante y gráficas tridimensionales. Las gráficas bidimensionales indicaron 2 picos de espectro de fluorescencia, 1 en la región azul-verde $(420-600 \mathrm{~nm})$ y 1 en la región roja $(640-720 \mathrm{~nm})$ del espectro visible. Debido a la naturaleza asimétrica de estos picos se desarrollaron polinomiales de quinto orden para diferenciar entre 4 dietas. La confiabilidad estadística fue alta cuando se discrimino entre dietas que 
spectrum. Because of the asymmetrical nature of these peaks, fifth-order polynomials were developed to differentiate among the 4 diets. Statistical reliability was high when discriminating between diets containing no tarbush leaf and the diets containing $30 \%$ tarbush leaf; however, it was not possible to statistically separate diets containing intermediate $(10$ and $20 \%$ ) amounts of tarbush leaf material from each other or from the 2 extremes $(0$ and $30 \%$ tarbush leaf). These results suggest spectral signatures arising from fluorometry data may be useful for differentiating among botanical composition diets that differ in plant form, but that a multivariate approach may require large sample sizes.

Key Words: Cattle, botanical composition, fluorescence, xenon fluorometry, fecal fluorophores

no contenían hojas de "Tarbush" y dietas conteniendo $30 \%$ de hojas de "Tarbush"; sin embargo, no fue posible separar estadísticamente las dietas que contenían cantidades intermedias (10 a $20 \%)$ de hojas de "Tarbush", no se pudieron separar entre ellas o de las otras 2 dietas extremos (0 y 30\% de hojas de "Tarbush". Estos resultados sugieren que firmas espectrales que surgen de los datos de la flurometría pueden ser útiles para diferenciar entre la composición botánica de dietas que difieren en la forma de la planta, pero se puede requerir un análisis multivariado para tamaños de muestra grandes

Determining the components comprising free-ranging herbivore diets is crucial to evaluating the nutritional well being and implementing herbivore management as well as maintaining positive plant relationships within ecological communities. Therefore, it is essential for managers to not only know what kind and amount of forages are available, but also which species are actually being eaten.
Diets are currently determined using various techniques. Probably the oldest and least automated technique is that of direct observation of foraging animals (Bjugstad et al. 1970). The bite count procedure, as it is frequently called, is still used (Doherty et al. 1999); yet, it is often inappropriate for some animal species and landscapes, and is always of concern scientifically because of the ever-present effect of observer influence. All other animal-based techniques require sampling digesta from 1 or more locations along the digestive tract (Holechek et al. 1984). The microhistological technique is the predominant method currently used for identifying dietary botanical composition of freeranging animals (Bennett et al. 1999, Bontti et al. 1999), with feces being the most commonly used samples since they represent a broad spatial and temporal range of dietary intakes (Norbury and Sanson 1992). Plant fragments too small to identify taxonomically, the overestimation of indigestible materials and the underestimation of readily digested materials such as leaf material, are just some of the problems that beset microhistological analysis. A major limitation to this technique as a management tool is the amount of time required for sample preparation and analysis thus preventing its usefulness in making real-time management decisions. Two recent automated techniques for determining botanical composition of animal diets having shorter analytical time requirements are near infrared reflectance spectroscopy (NIRS); (Garcia-Criado et al. 1991, Walker et al. 1998) and laser induced fluorescence (LIF); (Anderson et al. 1996, 1998). Although NIRS (Foley et al. 1998) and fluorometry (Lakowitz 1983, Guilbault 1990), of which LIF is one type, both rely on molecular properties, they differ in several important ways (Table 1).

\section{The Fluorometric Technique}

Fluorometry involves capturing light emitted from an excited molecule. All materials will emit fluorescence if excited with the proper excitation wavelength (Brach et al. 1977). Excitation is accomplished with an energy source, such as a xenon arc lamp or laser. This source, when focused at specific wavelengths and directed at a material, excites outer shell electrons from a ground state to a higher energy state. After excitation the electrons fall back to their ground state, many in a cascade fashion, and give off energy in the form of heat and light. The light emitted as a result of excitation has a longer wavelength than the excitation light and is termed fluorescence or more generally luminescence. This emitted light, when captured by a photo diode array, produces a unique spectral fluorescence fingerprint. These fluorophores and their unique individual fluorescence characteristics form the basis for identification. The objective of this research was to evaluate several statistical approaches using the entire spectral fingerprint to determine differences among fluorophores in a chloroform filtrate of feces from lambs fed differing diets.

\section{Materials and Methods}

Feces from 13 ruminally cannulated Polypay x Rambouillet lambs were fed a basal diet of tobosa (Pleuraphis mutica Buckley) hay with 0,10, 20, and 30\% tarbush (Flourensia cernua D C.) leaf was added to provide 4 dietary treatments. The feces collected were taken in conjunction with a metabolism study previously reported by King et al. (1996). Collection of the samples used in these fluorometry analyses and the sample preparation procedures has been previously described by Anderson et al. (1996) who used laserinduced fluorescence (LIF) to establish differences among these same diets.

This study differed from previous research (Anderson et al. 1996) in 3 ways. First, chloroform $\left(\mathrm{CHCl}_{3}\right)$, an organic polar solvent having a dipole moment

Table 1. Comparison of near infrared reflectance spectroscopy (NIRS) and fluorometry.

\begin{tabular}{|c|c|c|}
\hline Characteristics & NIRS & Fluorometry \\
\hline Measures & Vibrational energies (>700 nm) & Electron transitions (190 to $800 \mathrm{~nm}$ ) \\
\hline Pattern recognition & $\begin{array}{l}\text { Focuses on blended chemical structures } \\
\text { (many 2D response curves) }\end{array}$ & $\begin{array}{l}\text { Focuses on specific chemical structures } \\
\text { (specific } 2 \mathrm{D} \text { curves to } 5 \mathrm{D}^{1} \text { response surfaces) }\end{array}$ \\
\hline Sample state & $\begin{array}{l}\text { Choice of specific solvents required (many } \\
\text { materials absorb) }\end{array}$ & $\begin{array}{l}\text { Many polar \& non-polar solvents available } \\
\text { (fewer materials fluoresce) }\end{array}$ \\
\hline Post processing data & $\begin{array}{l}\text { Complex algorithms "trainable" for indirect } \\
\text { determination of alternative characteristics }\end{array}$ & $\begin{array}{l}\text { Simple algorithms "trainable" for indirect determination of } \\
\text { alternative characteristics }\end{array}$ \\
\hline
\end{tabular}

${ }^{1}$ Fluorescence lifetime represents the fourth dimension and rotational anisotropy* (the rate at which the fluorophore rotates in a liquid or gaseous solvent based on the fluorophore's size and the solvent's viscosity) represents the fifth dimension.

* Lakowitz, J. R. 1983. Principles of Fluorescence Spectroscopy. Plenum Press, New York, NY. 
slightly less than that of water, containing fecal pellet filtrate was exposed to UV light from a xenon arc lamp instead of a laser. Second, the continuous fluorescence spectrum for 6 excitation wavelengths $(310,320,330,340,350$, and $355 \mathrm{~nm})$ was used to determine differences among the diets instead of only evaluating individual peak features. Third, the fecal pellets were exposed at room temperature to chloroform for 24 hours, a shorter period of time than previously used, before the $\mathrm{CHCl}_{3}$ extract was filtered through No. 4 Whatman Filter Paper. All pellets were intact and immediately removed before filtration except for one, a $100 \%$ tobosa diet fecal pellet in which the pellet had been ground through a Wiley mill to pass a 40mesh $(0.5 \mathrm{~mm})$ screen before being placed in the chloroform. We did not consider the physical condition of the fecal material to be of concern since Anderson et al. (1996) demonstrated similar spectral signatures using feces from these same lambs when comparing ground and intact sheep fecal pellets. For this study, fecal pellets from only 13 of the original 16 lambs were available (King et al. 1996, Anderson et al. 1996). Lambs 1-3 received only the basal diet consisting of tobosa hay, lambs 4-6 received a diet consisting of $90 \%$ tobosa hay and $10 \%$ tarbush leaf, lambs $7-9$ received a diet consisting of $80 \%$ tobosa hay and $20 \%$ tarbush leaf and lambs 10-13 received a diet consisting of $70 \%$ tobosa hay and $30 \%$ tarbush leaf.

Fecal filtrate was prepared and evaluated using a fluorometer at Sandia National Laboratory, Albuquerque, N. M. The fluorometer had as an excitation source a 150 watt, high-pressure xenon arc lamp (Oriel Model 68805 arc lamp with xenon bulb Model 6254). White light from the xenon lamp was focused into an F/4, 1/8 meter double monochromator (CVI Model 120, 200-400 nm range, $5 \mathrm{~nm}$ steps, $7 \mathrm{~nm}$ bandwidth) to reduce scattered light outside of the pass band of the monochromator. Light from the monochromator was then imaged into the center of an RF3010-T FUV ultraviolet quartz sample cell (Spectrocell, Oreland, Penn). Scattered light and fluorescence from the chloroform filtrate was detected at 90 degrees to the incident excitation source. Excitation light was imaged into the entrance slit of an F/4, 1/8 meter imaging spectrometer (ISA Jobin Yvon, Edison, N. J., 200-700 $\mathrm{nm}$ range, $5 \mathrm{~nm}$ resolution). A 1,024-element intensified Reticon array (Model 1420, EG\&G Princeton Applied Research, Trenton, N.J.) detected the light at the image plane. The detection spectrometer had $5 \mathrm{~nm}$ resolution. A calibrated $\mathrm{D}_{2}$ lamp was used to determine the response of the detector system in the spectral range 200$400 \mathrm{~nm}$. The spectrum of the $\mathrm{D}_{2}$ lamp was calibrated by the manufacturer in accordance with the National Institute of Standards and Technology (NIST) standards. The relative output of the xenon lamp through the monochromator was measured using an Ophir Model PD-300UV colorimeter.

Five excitation wavelengths $(310,320$, 330,340 , and $350 \mathrm{~nm}$ ) were selected for evaluation by 1 author (Tisone) based on his experience with fluorescence spectra. These 5 wavelengths produced the most visually prominent and distinct fluorescence features from among the 200 to 400 $\mathrm{nm}$ range of excitation wavelengths associated with response surfaces. A sixth excitation wavelength $(355 \mathrm{~nm})$ was also selected, corresponding to the single excitation wavelength previously used to produce LIF on samples of this same fecal material as previously reported (Anderson et al. 1996). Light intensity counts at each excitation wavelength were measured at fluorescent wavelengths between 175 and $818 \mathrm{~nm}$ in $0.63 \mathrm{~nm}$ increments. This resulted in a total of $n=1,024$ pairs, each consisting of a fluorescent wavelength and an intensity count.

In previous work, Anderson et al. (1996) used LIF information from distinct peaks in the red and blue-green regions of the visible light spectrum to conduct statistical analyses. Responses were analyzed by analysis of variance using intensity counts and wavelengths for each peak and the $\mathrm{red} / \mathrm{blue}$ count ratio. In addition, only univariate (i.e., 1 response at a time) statistical analyses were conducted.

This study examined the 4 dietary treatments using the entire spectrum of fluorescence light intensities, necessitating a more complex statistical sequence requiring 5 analyses. First, bivariate plots of light intensities versus fluorescence wavelengths were examined to decide on appropriate regression models. Next, regression models were fitted and the fitted regression coefficients were extracted for use in the next 3 statistical techniques to discriminate among diets. Given that a regression model is a good fit, the regression coefficients contain all statistical information about the shape of the response curve. Thus, the dimensionality of the problem was reduced from $2 \mathrm{n}$ (in this case 2,048) down to $k=$ the number of regression coefficients. In addition, 2 of the last 3 techniques (discriminant analysis and 3-dimensional plots) add a multivari- ate component to the problem of distinguishing among diets by using more than 1 response at a time. The sequence of the 5 interrelated statistical techniques is now discussed in detail.

\section{Two-dimensional Plots}

Fluorescent light intensity (counts) was plotted against fluorescent wavelengths for each of the 6 excitation wavelengths using the GPLOT procedure in SAS (SAS Institute 1990b, 1990c). All data were plotted on the same scale to help visually distinguish similarities and differences among the 4 tarbush leaf treatments and to decide on appropriate regression models. Because of the consistent bimodal nature of the $x-y$ plots with individual peaks of different magnitudes in the blue-green and red regions of the visible spectrum across all diets and animals, we decided to fit a polynomial to each of these regions for each of the 6 excitation wavelengths. A fifth-order polynomial was chosen because of slope asymmetry among the individual peaks.

\section{Polynomial Regression Models}

The fifth-order polynomial regression model (Neter et al. 1996) is given by

$Y_{i}=\beta_{0}+\beta_{1} X_{i}+\beta_{2} X_{i}^{2}+\beta_{3} X_{i}^{3}+\beta_{4} X_{i}^{4}+\beta_{5} X_{i}{ }^{5}$ $+\epsilon_{\mathrm{i}}$,

where $\mathrm{Y}_{\mathrm{i}}$ is the intensity count at fluorescent wavelength $i$, for $i=1$ to 1,024 ,

$\beta_{0}, \beta_{1}, \ldots, \beta_{5}$ are (unknown) regression parameters,

$\mathrm{X}_{\mathrm{i}}$ is the $\mathrm{i}^{\text {th }}$ fluorescent wavelength which is a fixed constant and ranges from 175 to $818 \mathrm{~nm}$,

$\mathrm{X}_{\mathrm{i}}{ }^{2}, \ldots . \mathrm{X}_{\mathrm{i}}{ }^{5}$ are the higher powers of fluorescent wavelengths, and

$\epsilon_{\mathrm{i}}$ are errors which are independent and identically distributed as $\mathrm{N}\left(0, \sigma^{2}\right)$.

The REG procedure in SAS (SAS Institute 1989b) was used to model the data. There were 13 fitted models for each of the 6 excitation wavelengths and 2 regions of the visible spectrum (blue, green, or red), 1 for each lamb, with each model containing 6 regression coefficients. These regression coefficients were output for use in succeeding statistical analyses.

\section{Confidence Interval Plots}

Confidence interval plots represent a univariate statistical technique. After polynomials models were fitted, similarities and differences among the 4 tobosa diet models were examined using the individual regression coefficients (e.g., we compared intercepts for all 13 models of sam- 
ples in chloroform). To statistically compare regression coefficients, it was necessary to have information about the reliability or precision of the estimates. Therefore, confidence intervals incorporating information from both the regression coefficient and its variability were used to compare coefficients for a particular term (e.g., the intercept) across diets. To view these diet comparisons graphically, confidence interval plots for each term were constructed (intercept, linear term, etc.) for each excitation wavelength. Identifiers for the 13 lambs fed with the 4 diets were represented along the vertical (Y) axis, and first-order regression coefficient estimates with their $95 \%$ confidence intervals were plotted on the horizontal (X) axis. For each fluorescent region (blue, green or red) within each excitation wavelength, there were 6 such plots, 1 for each regression coefficient. The plots were constructed using the PLOT procedure in SAS (SAS Institute 1990a). These plots provided a subjective, graphical way to compare the treatments univariately (i.e., 1 regression coefficient at a time). Discriminant analysis was used to compare treatments using all coefficients at the same time to distinguish more objectively among treatments.

\section{Discriminant Analysis}

Discriminant analysis, also known as discriminant function analysis, is a multivariate technique designed to address problems arising due to classification. In plant taxonomy, discriminant analysis has been used to classify an individual into 1 of several related species (Morrison 1976, Johnson and Wichern 1988). In general, data from individuals from several known, mutually exclusive classes are used to develop rules (discriminant functions) which will then allow classification of an unknown individual into 1 of the classes.

Implementation of discriminant analysis involves several steps. First, a statistical metric distance to the sample mean of each class (Mahalanobis distance) is determined for every individual in the data set. These distances are based on the individual's multivariate measures and are scaled relative to the variability associated with each variable. The individuals' true classifications and these metric distances are then used to develop formulas for estimating the probability that any individual belongs to a particular class. Using these formulas, the probability that an individual (whose classification is unknown) belongs to a class can be estimated for each class based on the individual's distances to the class means. The individual is then predicted to belong to the class for which the individual has the highest probability of belonging.

Pairwise generalized-squared distances are a unitless measure of the distances between class means-again, scaled relative to the variability in each variable. The magnitudes of these squared distances can give insight into the potential for separating 2 treatments.

To evaluate how well the discriminant analysis classified an individual, cross-validation was used. In the cross-validation procedure, 1 of the individuals is deleted while the remaining individuals are used to build the discriminant function. The deleted individual is then classified based on this new discriminant function. This process is repeated for each individual in the data set, and the number of mis-specifications are totaled to obtain the misclassification rates for each class

In these data, there were 4 classes $(\mathrm{c}=$ 4) representing the 4 diets, 6 classification variables (the intercept and the 5 estimated regression coefficients from the fifth-order polynomial model), and $n=13$ lambs (4 for $70 \%$ tobosa mixed with $30 \%$ tarbush leaf, and 3 each for the remaining three diets). Discriminant analysis was used to develop classification rules, classify each lamb using cross-validation, and then determine if a lamb was properly classified into the correct diet class, all based on the values of the polynomial regression coefficients. The DISCRIM procedure of SAS (SAS Institute 1989a) was used to perform these analyses.

Having 13 observations limited the num-

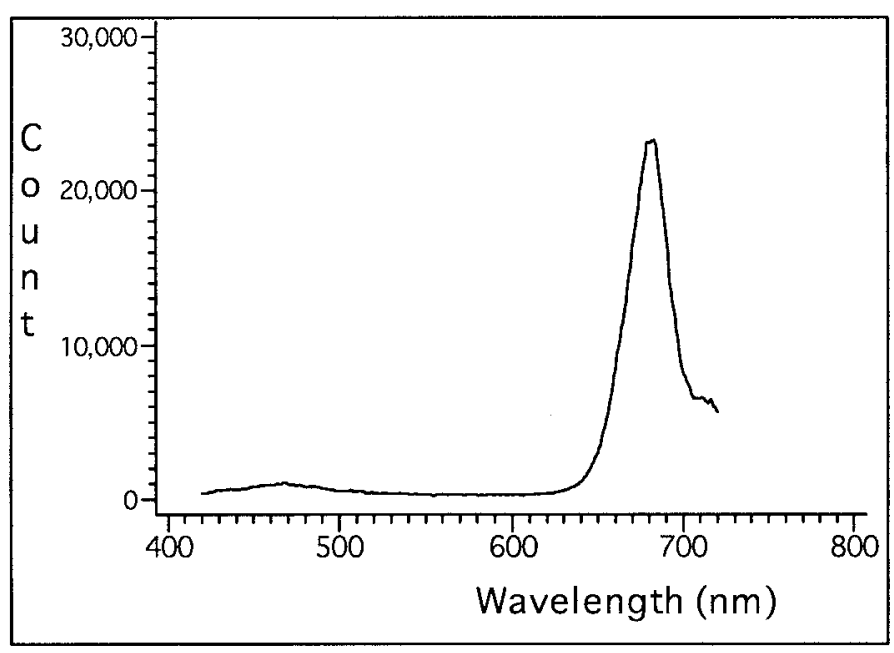

Fig. 1. Two dimensional plots of a raw fluorescence signature obtained from chloroform filtrate excited with a xenon light at $355 \mathrm{~nm}$, obtained from lamb 1's feces representing a $100 \%$ tobosa hay diet. Plot represents fluorescence intensity (counts) vs. fluorescence wavelengths between 420 and $720 \mathrm{~nm}$. ber of variables that could be examined at one time using discriminant analysis.

\section{Three-dimensional Plots}

Finally, 3-dimensional plots of the polynomial regression coefficients were used to study the spatial relationships among the 4 diet treatments graphically (JMP software, SAS Institute 1995). All subsets of 3 coefficients were picked and plotted on 3 axes. Changing the orientation of the axes (i.e., by rotating the axes at different angles) helped in understanding how the lambs were assigned to the various classifications, and which variables effectively separated the treatment groups spatially. This provides information regarding the utility of including each of the variables (regression coefficients) in the discriminant analysis. After choosing the coefficients that facilitated separation of the observations, the discriminant function analyses were performed again, using the DISCRIM procedure in SAS. Using variables that do not add useful information reduces the ability of many procedures to correctly distinguish among individuals from different treatments.

\section{Results and Discussion}

\section{Two-dimensional Plots}

Initially, plots of the fluorescent intensity counts versus fluorescent wavelengths were evaluated. In general, the feces from all 13 lambs at all 6 excitation wavelengths had a sharp distinct tall peak in the red $(640-720 \mathrm{~nm})$ and a relatively short broad peak in the blue-green (420-600 


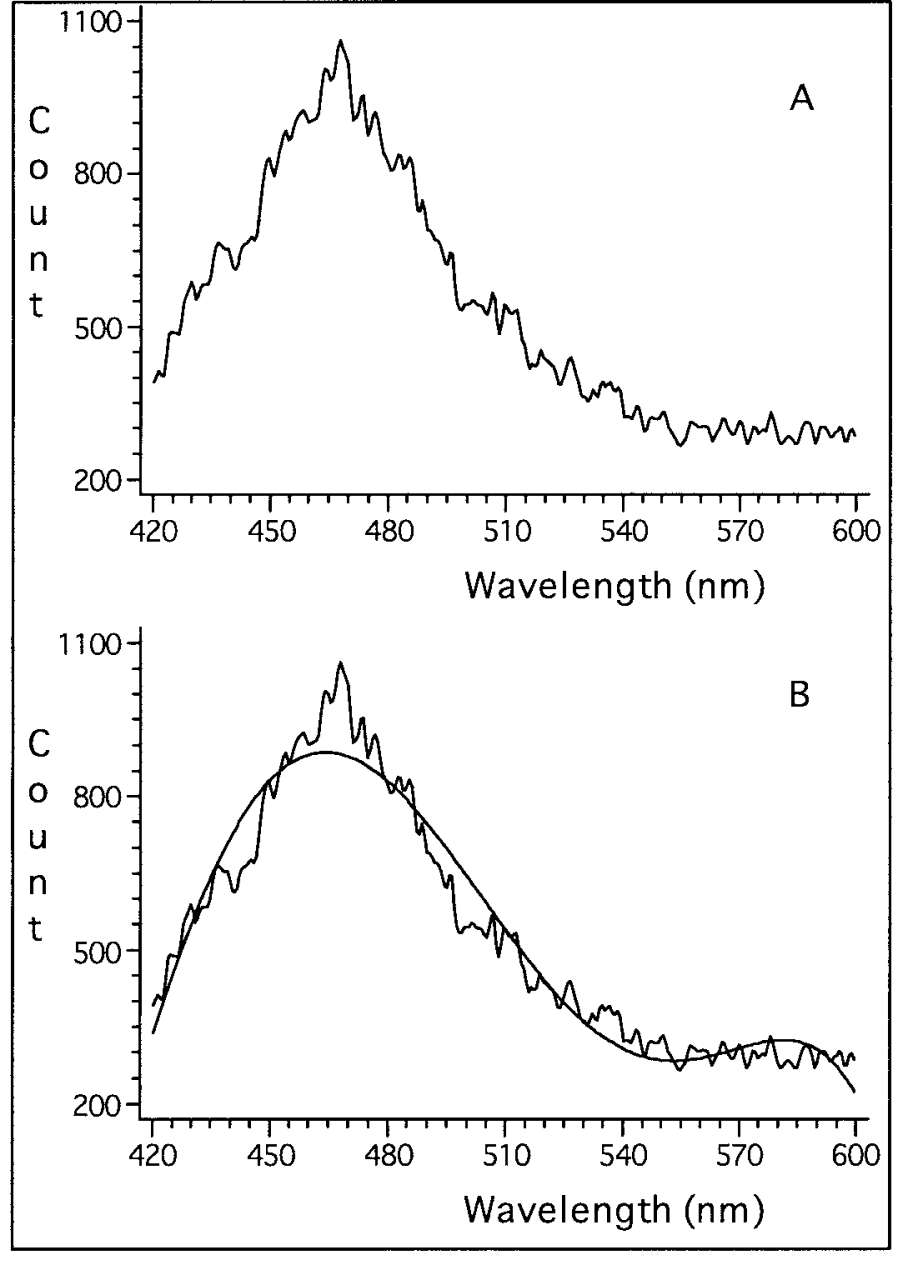

Fig. 2. Two dimensional plots of a raw fluorescence signature obtained from chloroform filtrate excited with a xenon light at $355 \mathrm{~nm}$, obtained from lamb 1's feces representing a $100 \%$ tobosa hay diet. Plot $(\mathrm{A})$ is the same data as for Fig. 1 but only for the blue-green region $(420-600 \mathrm{~nm})$ of the visible spectrum. Plot $(B)$ represents a fifth-order polynomial superimposed over the blue-green region of the fluorescence spectrum.

$\mathrm{nm}$ ) region of the visible spectrum. This bimodal characteristic was similar to that previously reported by Anderson et al. (1996) for these same feces when excited with Laser-Induced Fluorescence. Figure 1 depicts the fecal spectral signature from lamb 1 fed only the basal diet consisting of tobosa hay, excited at $355 \mathrm{~nm}$ over the range 420 to $720 \mathrm{~nm}$. Figure $2 \mathrm{~A}$ is from the same data for only the blue-green region. The curves were bimodal among all plots of the 6 different excitation wavelengths.

Of the 6 excitation wavelengths for which data were collected, only the extreme and middle excitation wavelengths $(310,330$, and $355 \mathrm{~nm})$ were used in further statistical procedures. As the other 3 excitation wavelengths were at intermediate levels (320, 340, and 350), they should not contribute much additional information in the diet characterizations. gested a fifth-order polynomial model would capture most of the peak curvatures in both the red and blue-green regions of the fluorescence spectrum, including a commonly visible "shoulder" in the red region between 700 and $720 \mathrm{~nm}$. Because of the magnitude of the X-values (fluorescent wavelengths), there was severe collinearity (linear relationships) among the predictors, $\mathrm{X}, \mathrm{X}^{2}, \ldots \mathrm{X}^{5}$. That is, there were high pairwise correlations between $X$ and $\mathrm{X}^{2}$, etc. This caused the polynomial regressions to be unstable, and resulted in the regression procedure incorrectly reporting coefficient estimates that were "biased" and "not unique." This is a common computational problem with polynomial models and was solved by centering the data at 0 (by subtracting the mean of the range of wavelengths) and scaling the range of the data to be approximately between -2 and +2 (by dividing by an appropriate constant) (Aiken and West 1991). For example, for the 420 to $600 \mathrm{~nm}$ range, the origin was shifted by subtracting 510 and the resulting deviations were divided by 45 .

For each of the replicates at the excitation wavelengths of 310,330 , and $355 \mathrm{~nm}$, a fifth-order polynomial equation was developed. After scaling, the fitted models had high R-square values, ranging from 0.908 to 0.998 . Most of the regression coefficients were significant at the 5\% level (e.g., of the 13 fitted models for the blue-green region at $355 \mathrm{~nm}$, only 4 of 78 regression coefficients were not significant, see Table 2).

Summaries from the fitted model with estimated regression coefficients, Mean Square Error, and R-square for the bluegreen and red regions at excitation wavelength $355 \mathrm{~nm}$ are given in Table 2. Figure $2 \mathrm{~B}$ is a plot of the same data from Figures 1 and $2 \mathrm{~A}$ with the fitted polynomial model from Table 2 superimposed.

\section{Confidence Interval Plots}

These plots visually depict how the 4 diets differed or were similar with respect to each term in the model. Coefficients that were similar had overlapping $95 \%$ confidence intervals while coefficients that were different had non-overlapping $95 \%$ confidence intervals. The latter was the case for all regression coefficients except the fourth-order term. The control diet (0\% tarbush leaf) and the diet containing 30\% tarbush leaf material, were readily distinguishable most of the time (for the blue-green region at $355 \mathrm{~nm}, 5$ out of 6 confidence intervals plots were readily distinguishable). Five of the 6 plots from 
samples excited at $355 \mathrm{~nm}$ in the bluegreen region indicated separation of the control diet from the diet containing the maximum amount of tarbush leaf material $(30 \%)$, while neither of the other 2 diets containing $10 \%$ and $20 \%$ tarbush leaf material were visually distinguishable in any of the 6 plots. The models developed for the blue-green region of the fluorescence spectrum showed more visual separation than the models depicting the red region. Similar results were obtained for the other excitation wavelengths.

Plots of confidence intervals for each regression term suggested a possibility of separating the control diet from the diet containing 30\% tarbush leaf material. To illustrate, Figure 3 shows a plot of the $95 \%$ confidence intervals for the firstorder regression coefficient estimates for excitation wavelength $355 \mathrm{~nm}$ with emission in the blue-green spectral region. The vertical axis identifies the 13 lambs and the diets to which they had been randomly assigned. This plot shows the first-order coefficients are reasonably differentiated between the $70 \%$ and $100 \%$ tobosa diets, but not differentiated between the $80 \%$ and $90 \%$ tobosa diets. The extreme diets are generally differentiated from the mid-

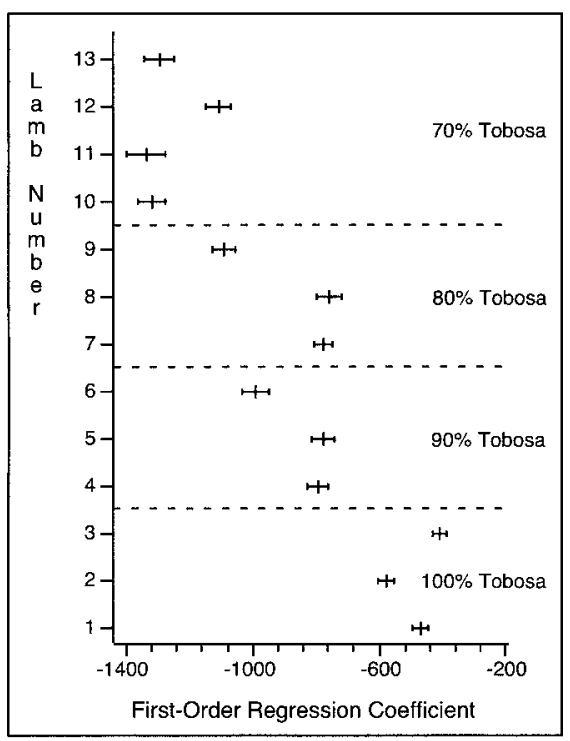

Fig. 3. First-order regression coefficient estimates of fluorometry data obtained from chloroform filtrate of fecal samples from 13 different lambs fed a basal diet of tobosa hay containing 4 levels $(0,10,20$, and $30 \%$ ) of tarbush leaf. The middle vertical line on each symbol represents the linear coefficient point estimate, while the outer vertical lines represent the $95 \%$ confidence interval. The diets having estimates that are furthest apart are the most statistically dissimilar.

Table 2. Estimated regression coefficients of fluorescence data in the blue-green $(420-600 \mathrm{~nm})$ and red $(640-720 \mathrm{~nm})^{1}$ regions of the visible spectrum obtained from the excitation of chloroform filtrate of lamb fecal pellets excited with a xenon lamp focused at $355 \mathrm{~nm}$ using four diets differing in tarbush leaf content with mean square error (MSE) and coefficient of determination $\left(R^{2}\right)$. Regression coefficients without " $n$ " below the number are significant $(\alpha=0.05)$.

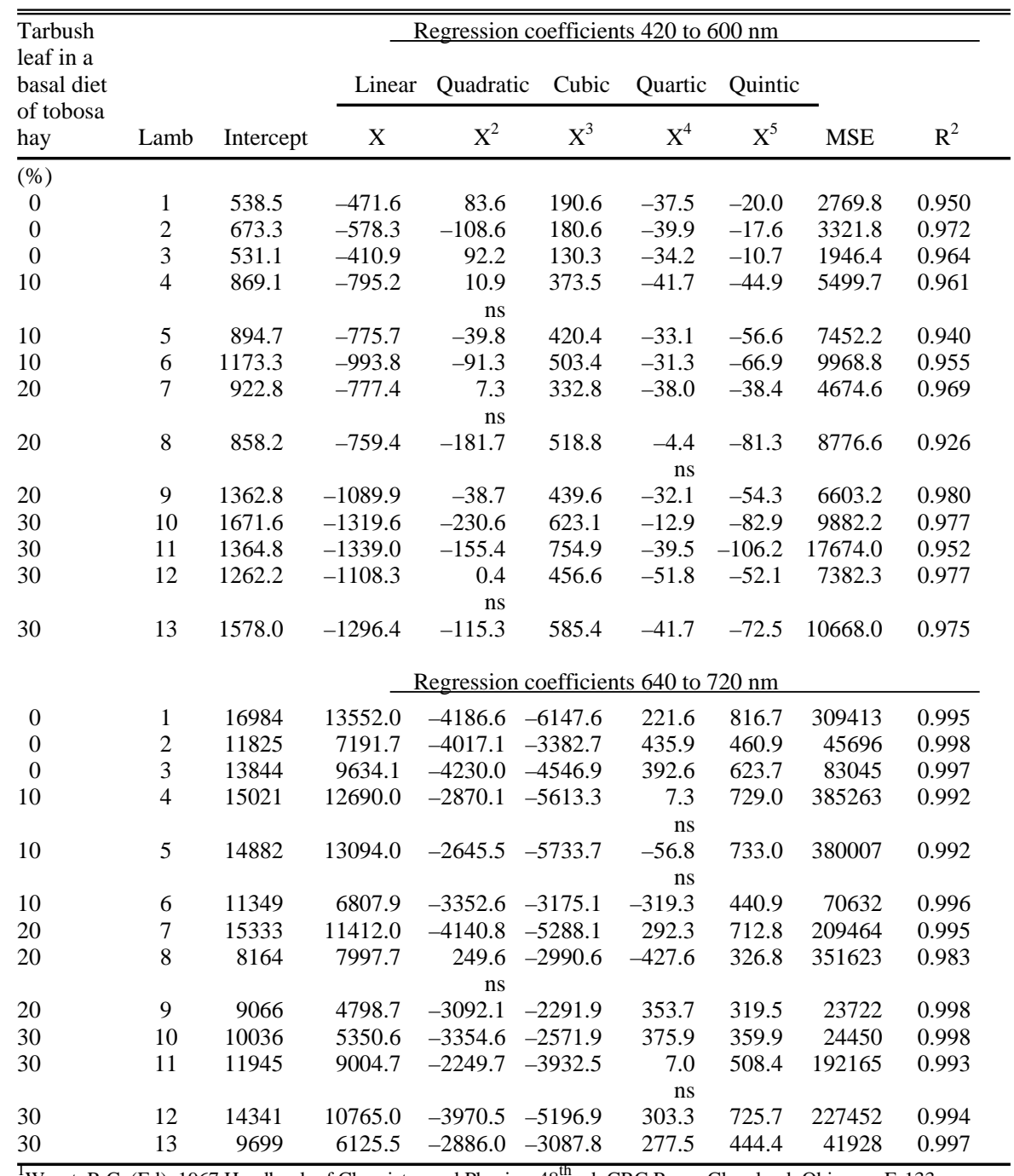

Weast, R.C. (Ed). 1967 Handbook of Chemistry and Physics, $48^{\text {th }}$ ed. CRC Press, Cleveland, Ohio, pp. E-133.

dle diets, but not completely. For example, the confidence intervals for lamb 12 (consuming 30\% tarbush leaf) and lamb 9 (consuming 20\% tarbush leaf) overlap. This and similar plots suggest that firstorder regression coefficient estimates are useful in separating lamb diets consisting of $30 \%$ tarbush leaf content from diets not containing tarbush leaf. However, at intermediate levels of tarbush leaf, it is not apparent that the first-order coefficients assist in separating diets-at least with these sample sizes.

\section{Discriminant Analysis}

Among the 4 dietary treatments, discriminant function analysis provided a means for detecting differences in multidi- mensional space, as opposed to the confidence-interval plots that examined 1 dimension at a time. In this approach, the 13 lambs fed the 4 diets were treated as observations and the 6 regression coefficients were treated as variables. Each of the 3 excitation wavelengths $(310,330$, and $355 \mathrm{~nm}$ ) was individually evaluated for both the blue-green and red regions of the visible spectrum. The number of lambs sampled (13) was not high compared to the number of variables (6); therefore, no sharp demarcation was possible between intermediate diets. However, it was possible with discriminant analysis to delineate between control diets and those containing $30 \%$ tarbush leaf material.

Pairwise generalized squared distances and misclassification rates give insight and 
Table 3. Misclassification results from discriminant analysis performed on polynomial regression coefficients obtained from fluorometry data of fecal chloroform filtrate differing in tarbush leaf content exposed to $355 \mathrm{~nm}$ xenon light. The values represent number of lambs classified incorrectly into a particular diet category by the discriminant analysis procedure when using spectral characteristics from both the blue-green $\left(420-600 \mathrm{~nm}^{1}\right)$ and red $\left(640-720 \mathrm{~nm}^{1}\right)$ regions of the visible spectrum.

\begin{tabular}{|c|c|c|c|c|c|c|c|c|}
\hline \multirow{3}{*}{$\begin{array}{l}\text { Tarbush leaf } \\
\text { in a basal diet } \\
\text { of tobosa hay }\end{array}$} & \multicolumn{8}{|c|}{ Wavelength } \\
\hline & \multicolumn{3}{|c|}{420 to $640 \mathrm{~nm}$} & & \multicolumn{3}{|c|}{640 to $720 \mathrm{~nm}$} & \multirow[b]{2}{*}{0} \\
\hline & 30 & 20 & 10 & 0 & 30 & 20 & 10 & \\
\hline$(\%)$ & --- & ---- & int- & ----- & ------- & - & )--- & ---- \\
\hline 30 & 3 & 1 & 0 & 0 & 2 & 2 & 0 & 0 \\
\hline 20 & 0 & 0 & 2 & 1 & 1 & 1 & 1 & 0 \\
\hline 10 & 0 & 3 & 0 & 0 & 1 & 1 & 1 & 0 \\
\hline 0 & 0 & 0 & 0 & 3 & 0 & 1 & 0 & 2 \\
\hline
\end{tabular}

${ }^{T}$ Weast, R.C. (Ed). 1967 Handbook of Chemistry and Physics, 48th ed. CRC Press, Cleveland, Ohio, pp. E-133.

help to illustrate our conclusions. The generalized squared distance between the control diet and the diet containing $30 \%$ tarbush leaf material, 106.62, was much larger than the distances between the other treatments, ranging between 5.48 and 41.58. Misclassification rates in Table 3 (listed for analysis of the blue-green and red regions of the visible spectrum at an excitation wavelength of $355 \mathrm{~nm}$ ) show that all 3 lambs fed the control diet containing no tarbush leaf (100\% tobosa hay) were correctly classified, and 3 out of the 4 lambs fed the diet containing 30\% tarbush leaf were correctly classified. Crossvalidation (the CROSSLIST option in the DISCRIM procedure in SAS 1989a) indicated the lambs fed the diets containing $10 \%$ and $20 \%$ tarbush leaves were likely to be misclassified-in general interchangeably. This indicated there was no sharp spectral separation at the excitation wavelength evaluated between the diets containing $10 \%$ and $20 \%$ tarbush leaf material.

Out of 7 misclassifications given in Table 3, five were strongly misclassified, with maximum classification probabilities greater than 0.95 . For example, for 1 lamb fed $10 \%$ tarbush leaf which was misclassified to the diet containing $20 \%$ tarbush leaf, the maximum classification probability was 0.97 while the probability of correctly classifying that lamb was much lower at only 0.02 . Two of the misclassifications were borderline with a maximum classification probability of 0.55 , but with only a slightly lower probability $(0.45)$ for being correctly classified to the diet containing $10 \%$ tarbush leaf. Even with the small sample size for each treatment, it was still possible to separate the control diet from the diet containing 30\% tarbush leaf material. The misclassification results from the red region of the visible spectrum for an excitation wavelength of $355 \mathrm{~nm}$ are

\section{Conclusions}

It was possible to discriminate $30 \%$ differences $(0 \%$ and $30 \%)$ but not smaller differences (10\% and $20 \%$ ) among chloroform filtrates from lamb feces that differed in tarbush leaf content using a series of 2dimensional plots, confidence interval plots, discriminant analysis, and 3-dimensional plots. Statistically, feces from control lambs fed no tarbush leaf material $(0 \%)$ had bimodal spectral signatures between 400 and $800 \mathrm{~nm}$ that were different from feces obtained from lambs that had been fed the basal diet but which contained 30\% tarbush leaf material. However, lambs fed a tobosa hay basal diet containing $10 \%$ and $20 \%$ tarbush leaf material could not be statistically separated.

Univariate analyses on single-peak information in Anderson et al. (1996) similarly distinguished between the control and 30\% tarbush leaf material in diets but also distinguished among intermediate diets. These single peaks were in the blue and red regions of the visible spectrum and made it possible to discriminate among the 4 diets in a linear fashion $(\mathrm{a}=0.05)$.

Multivariate techniques are, in general, more powerful than analogous univariate techniques but do require larger sample sizes to compensate for simultaneously fitting more parameters. In this set of analyses, the number of observations (lambs) was small $(n=13)$ relative to the number of variables and groups being used $(t=6$, $c=4)$. The small sample size likely resulted in the inability of multivariate analyses to separate the $10 \%$ and $20 \%$ tarbush leaf diets from the 2 extreme diets. However, these analyses do provide information about the entire fluorescence spectrum, summarizing that information in just 6 regression coefficients for each lamb and spectral region. In situations where more animals are available from which to obtain fecal samples, we expect this sequence of statistical techniques will be able to distinguish among diets.

These results suggest fluorometry in conjunction with multivariate statistical techniques show promise in distinguishing among fecal samples representing different diets, especially if numbers of animals sampled remains relatively large. It is the opinion of the authors that 20 to 30 animals allocated among the 4 diets would have substantially improved our ability to discriminate among the different diets.

\section{Future Work}

Calibration procedures following NIST standards should be conducted to evaluate 
long term instrument stability by comparing data taken from sub samples of a single sample that are randomly evaluated over time. Furthermore, a set of reference standards representing the materials being evaluated should be periodically evaluated to determine if spectral output changes among runs. If spectral fluorescence variability increases as a result of increased hours of xenon arc lamp use, this would be detected and appropriate data adjustments could be made. This information will be necessary to establish proper fluorometry protocol for determining botanical composition among sample mixtures.

Degradation of a xenon arc lamp does not occur over short periods of time. Therefore, this potential source of variability was not considered important in these data since it took only a few minutes to obtain data on each sample and the entire procedure lasted only a few hours.

\section{Literature Cited}

Aiken, L.S. and S.G. West. 1991. Multiple Regression: Testing and Interpreting Interactions. Sage Publications, Newbury Park.

Anderson, D. M., E. L. Fredrickson, P. Nachman, R.E. Estell, K.M. Havstad, and L.W. Murray. 1998. Laser-induced fluorescence (LIF) spectra of herbaceous and woody pre- and post- digested plant material. Anim. Feed Sci. Technol. 70:315-337.

Anderson, D.M., P. Nachman, R.E. Estell, T. Ruekgauer, K.M. Havstad, E.L. Fredrickson, and L..W. Murray. 1996. The potential of laser-induced fluorescence (LIF) spectra of sheep feces to determine diet botanical composition. Small Rum. Res. 21:1-10.

Bennett, L.L., A.C. Hammond, M.J. Williams, C.C. Chase Jr., and W.E. Kunkle. 1999. Diet selection by steers using microhistological and stable carbon isotope ratio analyses. J. Anim. Sci. 77:2252-2258.

Bontti, E.E., R.M. Boo, L.I. Lindstrom, and O.R. Elia. 1999. Botanical composition of cattle and vizcacha diets in central Argentina. J. Range Manage. 52:370-377.

Brach, E.J., J.M. Molnar, and J.J. Jasmin. 1977. Detection of lettuce maturity and variety by remote sensing techniques. J. Eng. Res. 22:45-54.

Bjugstad, A.J., H.S. Crawford, and D.L. Neal. 1970. Determining forage consumption by direct observation of domestic animals In: Range and wildlife habitat evaluation - A research symposium. USDA For. Serv. Misc. Pub. No 1147. 200 p.

Doherty, D.R., J. Vaad, G. Greathouse, A.P. Knight, T.W. Geary, and M.H. Ralphs. 1999. Locoweed bite count correlation with serum swainsonine levels in cattle. J. Anim. Sci. (Supp 1) 77:97.
Foley, W.J., A. McIlwee, I. Lawler, L. Aragones, A.P. Woolnough, and N. Berding. 1998. Ecological applications of near infrared reflectance spectroscopy - a tool for rapid, cost-effective prediction of the composition of plant and animal tissues and aspects of animal performance. Oecologia. 116:293-305.

Garcia-Criado, B., A. Garcia-Ciudus, and M.E. Perez-Corona. 1991. Prediction of botanical composition in grassland herbage samples by near-infrared reflectance spectroscopy. J. Sci. Food Agr. 57:507-515.

Guilbault, G.G., Editor. 1990. Practical fluorescence, $2^{\text {nd }}$ ed. Marcel Dekker, Inc, New York, NY.

Holechek, J.L., M. Vavra, and R.D. Pieper. 1984. Methods for determining the botanical composition, similarity, and overlap of range herbivore diets. In: Developing strategies for rangeland management. Westview Press, Boulder, Colo. pp. 425-471.

Johnson, R., and D. Wichern. 1988. Applied Multivariate Statistical Analysis, $2^{\text {nd }}$ ed. Prentice Hall, Englewood Cliffs, N.J.

King, D.W., R.E. Estell, E.L. Fredrickson, K.M. Havstad, J.D. Wallace, and L.W. Murray. 1996. Effects of Flourencia cernua ingestion on intake, digesta kinetics, and ruminal fermentation of sheep consuming tobosa. J. Range Manage. 49:325-330.

Krause, G.H. and E. Weis. 1984. Chlorophyll fluorescence as a tool in plant physiology. II. Interpretation of fluorescence signals. Photo. Res. 5:139-157.

Lakowitz, J. R. 1983. Principles of Fluorescence Spectroscopy. Plenum Press, New York, N.Y.

Lang, M., F. Stober, and H.K. Lichtenthaler. 1991. Fluorescence emission spectra of plant leaves and plant constituents. Rad. Environ. Biophys. 30:333-347.

Lichtenthaler, H.K. and J.S. Schweiger. 1998. Cell wall bound ferulic acid, the major substance of the blue-green fluorescence emission of plants. J. Plant Physiol. 152:272-282.

Morrison, D.F. 1976. Multivariate Statistical Methods, $2^{\text {nd }}$ ed. McGraw-Hill, New York, N.Y.

Neter, J., M.H. Kutner, C.J. Nachtsheim, and W. Wasserman. 1996. Applied Linear Regression Models. 3rd ed. Irwin, Chicago, Ill.

Norbury, G.L. and G.D. Sanson. 1992. Review: Problems with measuring diet selection of terrestrial mammalian herbivores. Aust. J. Ecol. 17:1-7.

SAS Institute Inc., 1989a. SAS / STATUser's Guide, Ver. 6, $4^{\text {th }}$ ed., Vol. 1, Cary NC: SAS Institute Inc., 943 pp.

SAS Institute Inc., 1989b. SAS / STAT User's Guide, Ver. 6, $4^{\text {th }}$ ed., Vol. 2, Cary NC: SAS Institute Inc., 846 pp.

SAS Institute Inc., 1990a. SAS - Procedure's Guide, Ver. 6, $3^{\text {rd }}$ ed., Cary NC: SAS Institute Inc., $705 \mathrm{pp}$.

SAS Institute Inc., 1990b. SAS / GRAPH Software: Ref. Ver. 6, $1^{\text {st }}$ ed., Vol. 1, Cary NC: SAS Institute Inc., 794 pp.
SAS Institute Inc., 1990c. SAS / GRAPH Software: Ref. Ver. 6, $1^{\text {st }}$ ed., Vol. 2, Cary NC: SAS Institute Inc., 664 pp.

SAS Institute Inc., 1995. JMP Statistics and Graphics Guide, Ver. 3.1, Cary NC: SAS Institute Inc., 593 pp.

Walker, J.W., D.H. Clark, and S.D. McCoy. 1998. Fecal NIRS for predicting percent leafy spurge in diets. J. Range Manage. $51: 450-455$.

Weast, R.C. (Ed). 1967. Handbook of Chemistry and Physics, 48th ed., CRC Press, Cleveland, Ohio, pp. E-133. 